\title{
Primary Yolk Sac (Endodermal Sinus) Tumour of the Vulva: A Case Report
}

\author{
Nagesh Babu Subrahmanya ${ }^{a}$ Surendra Nayak Kapadi ${ }^{a}$ T.A. Junaid ${ }^{b}$ \\ a Department of Histopathology, Maternity Hospital, and ${ }^{b}$ Department of Pathology, Faculty of Medicine, \\ Kuwait University, Jabriya, Kuwait
}

\section{Key Words}

Yolk sac tumour $\cdot$ Vulva $\cdot \alpha$-Fetoprotein

\begin{abstract}
Objective: To report a case of primary yolk sac (endodermal sinus) tumour (YST) of the vulva which is very rare and to highlight some unusual features of this tumour in the vulva. Clinical Presentation and Intervention: A 23-year-old woman presented with a 1-month swelling in the right labium majus that was non-tender and rapidly increasing in size. The mass was excised; it grossly measured $6 \times 5 \times 3 \mathrm{~cm}$ and was firm with a grey white cut surface. Microscopically it showed features of YST. The patient returned to the clinic only after 2 months with a recurrent mass of almost the same size with ipsilateral lymphadenopathy. At that time serum $\alpha$-fetoprotein showed only a mild increase (13.4 $\mu \mathrm{g} / \mathrm{l}$, normal: $0-10 \mu \mathrm{g} / \mathrm{l})$. Further management was not possible as she decided to return to her native country for treatment. A literature review shows that local excision with lymphadenectomy followed by cisplatin-based chemotherapy is the best mode of treatment for primary YST of the vulva. Conclusion: This case is presented for its rarity and to highlight the fact that serum $\alpha$-fetoprotein estimation may not aid in the primary diagnosis or detection of recurrence in patients on follow-up for YST arising in the vulva unlike those seen in the gonads.

Copyright $\odot 2010$ S. Karger AG, Basel
\end{abstract}

\section{Introduction}

Extragonadal yolk sac (endodermal sinus) tumours (YST) of the external genitalia represent an exceedingly rare malignancy in women. Traen et al. [1] reviewed 8 cases in 2004. Since then 3 more cases have been reported [2-4], making a total of 11 cases in the literature. Vulvar YST has shown some differences in behaviour from similar tumours at other more common sites (like ovary and mediastinum) that include absence of abnormal levels of $\alpha$-fetoprotein (AFP) in serum and a more aggressive behaviour [1]. This has implications in the management of this tumour. This case is the 12 th to be reported in the literature.

\section{Case Report}

A 23-year-old married nulligravid woman presented with a 1-month swelling in the right labium majus which was rapidly increasing in size. There was no significant medical or family history. Examination revealed a $7 \times 6 \mathrm{~cm}$ firm non-tender swelling occupying most of the right labium majus. Physical examination revealed no organomegaly in the pelvis or within the abdomen.

The mass was completely excised. Grossly, the mass measured $6 \times 5 \times 3 \mathrm{~cm}$ and weighed $58.8 \mathrm{~g}$. It was well circumscribed, firm with a grey white cut surface showing focal areas of haemorrhage. Microscopically the tumour comprised solid areas merging with other areas showing glandular and reticular patterns (fig. 1 ) in a

\section{KARGER}

Fax +4161306 1234 E-Mail karger@karger.ch www.karger.com
Dr. Nagesh Babu Subrahmanya

PO Box 2223

Al Ardiya 92400 (Kuwait)

Tel. +965 24992068

E-Mail nageshbabu_s1@rediffmail.com 


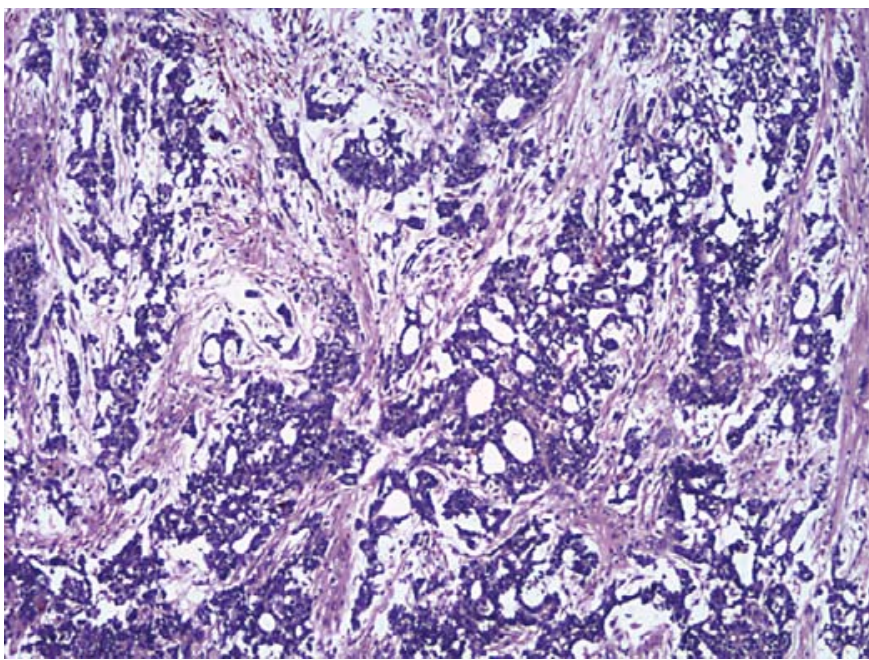

Fig. 1. Low-power microphotograph showing reticular and glandular patterns. HE. $\times 40$.

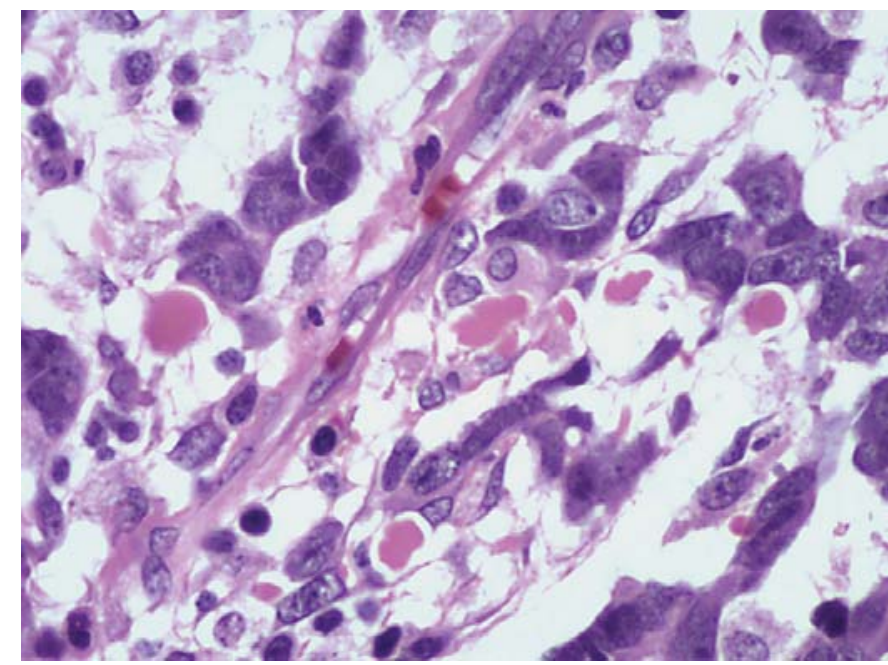

Fig. 3. Intracellular eosinophilic hyaline globules. HE. $\times 400$.

myxoid background. Few Schiller-Duval bodies (papillae with central vascular core surrounded by a single layer of tumour cells; fig. 2) were noted along with numerous periodic-acid-Schiff-positive hyaline globules (fig. 3). Solid areas showed numerous mitotic figures and areas of tumour cell necrosis. Immunohistochemistry showed that the tumour was focally positive for AFP (fig. 4) and diffusely positive for cytokeratin and $\alpha_{1}$-antitrypsin. A diagnosis of YST was made.

The patient returned to the clinic after 2 months with recurrence of the swelling of almost the same size with ipsilateral inguinal lymphadenopathy. Ultrasound examination of the pelvis showed a normal uterus and ovaries. Serum tumour marker estimation showed AFP of $13.4 \mu \mathrm{g} / \mathrm{l}$ (normal 0-10 $\mu \mathrm{g} / \mathrm{l}$ ), CA-125 II of

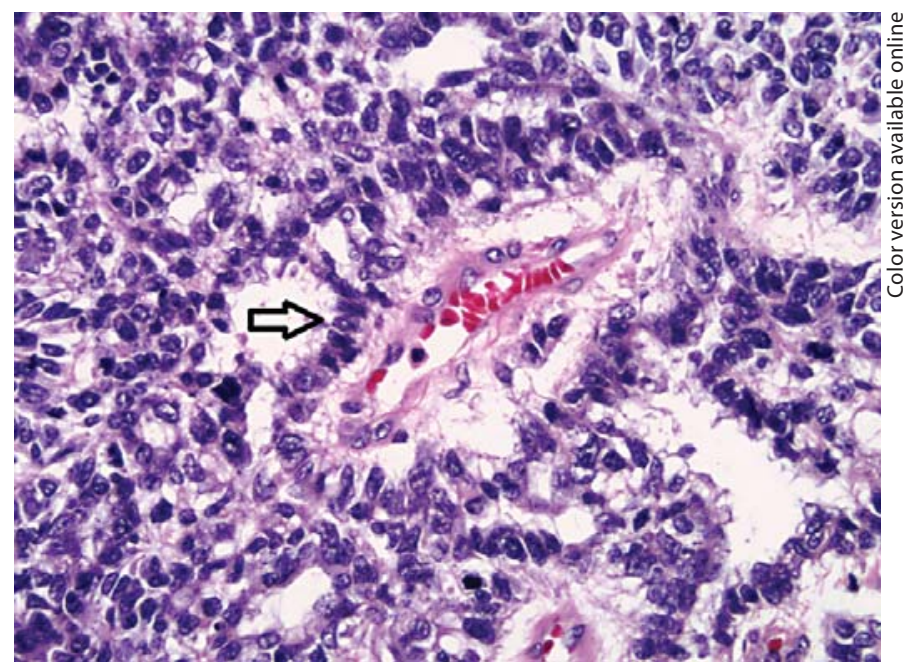

Fig. 2. Schiller-Duval body (arrow). HE. $\times 200$.

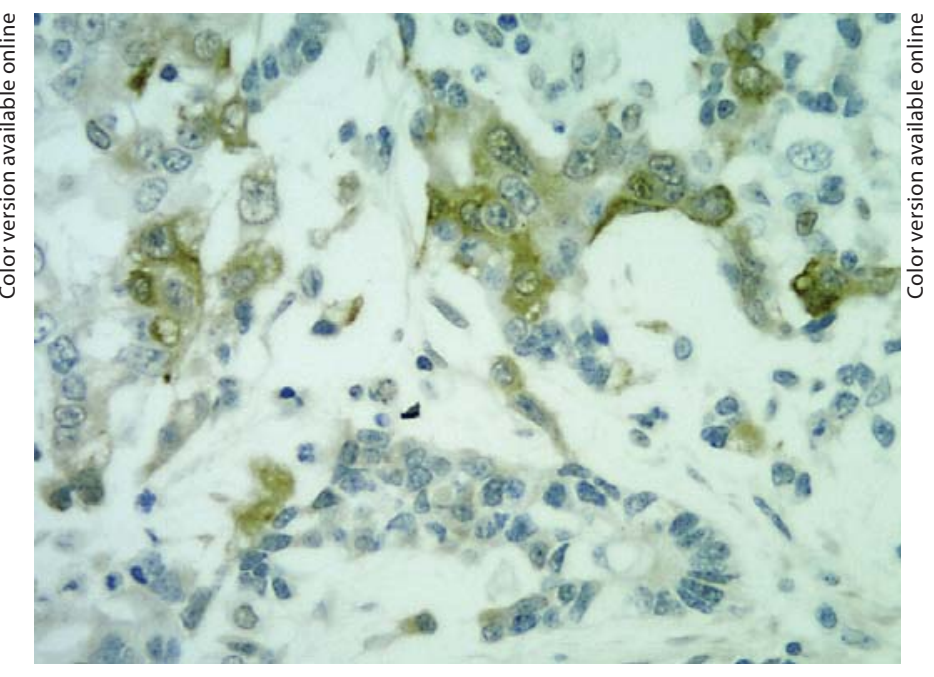

Fig. 4. Immunohistochemistry for AFP showing focal cytoplasmic positivity. $\times 200$.

$6.35 \mathrm{U} / \mathrm{ml}$ (normal $<35 \mathrm{U} / \mathrm{ml}$ ) and carcino-embryonic antigen of $1.66 \mu \mathrm{g} / \mathrm{l}$ (normal $<3.2 \mu \mathrm{g} / \mathrm{l}$ ), and $\beta$-human chorionic gonadotrophin was negative. She was referred to the oncology clinic for management but was lost to follow-up.

\section{Discussion}

Current evidence has provided support for Teilum's postulate that the YST is a unilaterally developed teratoma mimicking embryonal yolk sac tissue [5]. Extrago- 
nadal YST are uncommon and those involving the female genital tract even more so. The vagina and cervix are more commonly involved [6], and vulval involvement is extremely rare with only 11 cases reported so far [1-4]. Histogenesis of extragonadal germ cell tumours has been explained as due to the aberrant migration of germ cells during early embryonic life, which normally occurs from the yolk sac to genital ridges. A possible hypothesis for the tumours arising in the vulva is that they originate from misplaced germ cells which enter the vulva through the gubernaculum [7].

YST of the vulva commonly occurs in the second and third decades of life with a median age of 22.5 years. The youngest patient was 22 months and the oldest 52 years old [1]. The most common location within the vulva is the right labium majus.

AFP, an $\alpha_{1}$-globulin in serum, the level of which is about $41,697 \mathrm{ng} / \mathrm{ml}$ at birth, rapidly decreases to just 0 $20 \mathrm{ng} / \mathrm{ml}$ by 2 years of age [9]. It has been demonstrated that germ cell tumours in patients with elevated serum AFP are either composed entirely of or contain yolk sac elements [10]. Serum AFP determination is of value in monitoring the results of therapy and for early detection of recurrence and metastases. AFP levels fall postoperatively and, if there are no metastases, reach normal levels within 4-6 weeks. In our patient, pre-operative AFP was not determined as YST was not suspected. Often AFP estimation can be done after the histological diagnosis, since it has a half-life of 5 days and may still be estimated after surgery; if elevated this would be helpful. However, it was not done in our patient within 5 days. It was only assessed 2 months later when she came back with a re- currence. At that time it was only marginally elevated $(13.4 \mu \mathrm{g} / \mathrm{l}$, the normal range for our laboratory is $0-10$ $\mu \mathrm{g} / \mathrm{l})$. This is not a surprise as 6 of the 11 cases reported so far have shown normal AFP values [1-4, 7].

YST are highly aggressive. In the series by Kurman and Norris [11] on ovarian YST, the actuarial survival at 3 years was only $13 \%$. However, the introduction of multidrug chemotherapy has dramatically improved the survival rates [8]. The same is true of YST of the vulva where cisplatinum-based chemotherapy protocols have given a disease-free survival of 15-90 months [1-4]. Local excision with regional lymph node excision followed by cisplatinum-based chemotherapy (PEB regimen) seems to be the best mode of treatment for this tumour. The beneficial role of additional radiotherapy is not clearly established in the previous case studies. However, it may be of benefit in cases with recurrence and metastases to regional lymph nodes [2]. We did not have the opportunity to treat our patient with chemotherapy because she decided to leave Kuwait and return to her home country.

\section{Conclusion}

Primary YST of the vulva may be extremely rare with this case being only the twelfth in the world literature. However, it does figure in the differential diagnoses of a rapidly growing soft tissue mass in this region especially in a young adult. Estimation of AFP in serum may not aid in the primary diagnosis or in the detection of recurrence of this tumour.

\section{References}

1 Traen K, Logghe H, Maertens J, Mattelaere C, Moerman P, Vergote I: Endodermal sinus tumor of the vulva: successfully treated with high-dose chemotherapy. Int J Gynecol Cancer 2004;14:998-1003.

$\checkmark 2$ Khunamornpong S, Siriaunkgul S, Suprasert P, Chitapanarux I: Yolk sac tumour of vulva: a case report with long-term diseasefree survival. Gynecol Oncol 2005;97:238242.

>3 Basgul A, Gokaslan H, Kavak ZN, Eren FT, Bozkurt N. Primary yolk sac (endodermal sinus) tumour of the vulva: case report and review of the literature. Eur J Gynaecol Oncol 2006;27:395-398.

4 Niwa K, Onogi K, Wu Y, Tamaya T: Primary endodermal sinus tumor of the vulva in a 52-year-old woman with long-term survival: a case report. Eur J Gynaecol Oncol 2007;28: 506-508.

5 Gonzalez-Crussi F: The human yolk sac and yolk sac (endodermal sinus) tumour: a review. Perspect Pediatr Pathol 1979;5:179215.

6 Clement PB, Young RH, Scully RE: Extraovarian yolk sac tumours. Cancer 1988;62: 620-626.

7 Flanagan CW, Parker JR, Mannel RS, Min KW, Kida M: Primary endodermal sinus tumor of the vulva: a case report and review of the literature. Gynecol Oncol 1997;66:515518.

8 Gershenson DM, Del Junco G, Herson J, Rutledge FN: Endodermal sinus tumour of the ovary: the MD Anderson experience. Obstet Gynecol 1983;61:194-202.

$\checkmark 9$ Blohm ME, Vesterling-Horner D, Calaminus G, Gobel U: Alphh-1-fetoprotein (AFP) reference values in infants up to 2 years of age. Pediatr Hematol Oncol 1998;15:135142 .

10 Talerman A, Haije WG, Baggerman L: Serum alfa-fetoprotein (AFP) in patients with germ cell tumours of gonadal and extragonadal sites: correlation between endodermal sinus (yolk sac) tumour and raised serum AFP. Cancer 1980;46:380-385.

11 Kurman RJ, Norris HJ: Endodermal sinus tumours of the ovary: a clinical and pathological analysis. Cancer 1976;38:24042419 . 